\title{
Evolution of dioecy: can nuclear-cytoplasmic interactions select for maleness?
}

\author{
SANDRINE MAURICE*, ERIC BELHASSEN $\dagger$, DENIS COUVET $\ddagger$ \& PIERRE-HENRI \\ GOUYON \\ Laboratoire d'Evolution et Systématique des Végétaux, Bat 362, Université Paris Sud, 91405 Orsay Cedex, $\dagger$ ENSAM, \\ 2 Place Pierre Viala, 34000 Montpellier and $\ddagger$ Laboratoire d'Evolution, CEFE, Route de Mende, BP 5051, 34033 \\ Montpellier Cedex, France
}

\begin{abstract}
A model of evolution of reproductive systems, when sex is determined by both nuclear and cytoplasmic genes, is presented. Such a control of sex is known to facilitate the occurrence of female individuals in hermaphroditic populations, thus leading to gynodioecy. A two-cytotypes twonuclear loci (two alleles at each nuclear locus) model for gynodioecy has been developed previously. Such gynodioecious systems are usually considered as stable, i.e. not leading to dioecy. In order to find out if the presence of females can select for male individuals when sex determination is nuclear-cytoplasmic, we followed the evolution of alleles responsible for female sterility. These alleles can be at the preceding loci or at a third locus. We show that male individuals can be selected. Dioecy evolves in less restrictive conditions than under nuclear sex determination. The same also holds for trioecy (coexistence of females, hermaphrodites and males). Nuclear-cytoplasmic polymorphism can be maintained in these reproductive systems.
\end{abstract}

Keywords: cytoplasmic male sterility, dioecy, gynodioecy, reproductive systems, sex determination, trioecy.

\section{Introduction}

The evolution of dioecy from the hermaphrodite state has long been discussed but is still not fully understood. The selective force most commonly put forward is the avoidance of inbreeding (see Thomson \& Barrett, 1981, for references). Other explanations are based on resource allocation theories. Different sexual forms can be more or less efficient in gamete production, depending on their biology (Charnov et al., 1976). The total number of gametes produced by an individual can influence the chance of success of each gamete depending on the mode of pollination and seed dispersal; the evolution of dioecy has thus often been thought to be related to ecological conditions (Willson, 1979; see Thomson \& Brunet, 1990, for a review and discussion). All these explanations deal with the number of gametes that the different sexual types pass to the next generation and are synthesized by Charnov's 'evolutionary stable strategy' calculations based on a phenotypic model of sexual strategies (Charnov et al., 1976). Numerous genetic models involving male-sterile and female-sterile nuclear mutations also exist. These models give the same results as Charnov's calculations

\footnotetext{
${ }^{*}$ Correspondence.
}

except when they deal with genetic constraints or with inbreeding (Charlesworth \& Charlesworth, 1978; Gregorius et al., 1983).

Charlesworth \& Charlesworth (1978) have studied the influence of the recombination rate between the male sterility and the female sterility loci on the conditions that lead to dioecy, with different dominance coefficients of the sterility alleles: such constraints lead to equal or more restricted conditions for the evolution of dioecy compared with phenotypic models. Another genetic phenomenon that is known to influence the outcome of selection on sexual phenotypes is nuclear-cytoplasmic sex determination. Such a determination has been found in many wild and cultivated species (see Kaul, 1988, for a review). There are three reasons why the nuclear-cytoplasmic determination of sex can be important.

1 We already know that cytoplasmic or nuclear-cytoplasmic determination of sex allows the maintenance of gynodioecy under conditions when the population would be hermaphroditic if sex were controlled only by nuclear genes. These conditions are given by the relative female fertility of the two sex morphs, females and hermaphrodites. Several models show that cytoplasmic polymorphism, and thus females, can be maintained (Lewis, 1941; Lloyd, 1974: pollination limitation in females; Charlesworth, 1981; 
Delannay et al., 1981; Ross \& Gregorius, 1985; Gouyon et al., 1991: deleterious effect of the nuclear allele restoring male function; Frank, 1989: mutation and drift affecting cytotypes and nuclear restorers together with a deleterious effect of restorers).

2 Results from these models, combined with observations of high frequencies of females in natural populations of gynodioecious species with nuclearcytoplasmic determination of sex (Plantago lanceolata: Baker, 1963; Van Damme, 1983; Thymus vulgaris: Dommee et al., 1978; Belhassen et al., 1991; Origanum vulgare: Kheyr-Pour, 1980) raise the question of how the selection on the sex allocation of individuals producing pollen is affected. Indeed, the higher the frequency of females, the higher should be the success of male gametes. Selection for a male-biased sex allocation in hermaphrodites or even for completely male individuals is thus expected. This has been shown to be true for nuclear control of male sterility (Charlesworth \& Charlesworth, 1978).

3 Gynodioecy and dioecy are associated at the family level ( 88 per cent of families with gynodioecious species also contain dioecious species, a proportion that is much higher than in the whole flora: Maurice $e t$ al., 1993) and gynodioecy often involves nuclear-cytoplasmic determination of sex. We thus wonder if nuclear-cytoplasmic gynodioecy can lead to dioecy?

The question of male allocation in hermaphrodites has been explored when there is an entirely male-sterile cytotype (all individuals having this cytotype are female; cytotype here designates the cytoplasmic genotype, not the level of ploidy) and a second fully malefertile one (all individuals having this cytotype are hermaphroditic). In this case, the fertile cytotype acts as an isolated compartment for genes involved in pollen production (such as female-sterile alleles), so that conditions for males to evolve are the same as with nuclear sex determination (Charlesworth, 1989; Maurice et al., 1993; see Werren, 1987, for a similar process in the evolution of sex ratio). When one cytotype is fertile and one contains females and hermaphrodites, hermaphrodites can sometimes be selected to invest more in male function, but the fertile cytotype is then quickly lost (Maurice et al., 1993). Genetic studies (Plantago lanceolata: Van Damme, 1983; Thymus vulgaris: Belhassen et al., 1991) have shown that several cytotypes causing male sterility can be found within a single population. The presence of females in several cytotypes can be crucial for the maintenance of cytoplasmic polymorphism. Here we consider an extension of the simplified sex detemination proposed by Van Damme (1985) for gynodioecy in Plantago: there are two potentially male-sterile cytotypes and a nuclear locus that restores male fertility for each cytotype. This model has been explored for gynodioecy by Gouyon et al. (1991). In the following model, both cytotypes can yield females, hermaphrodites and males, depending on the nuclear genes. Using computer calculations, we search for the conditions that allow males to invade a gynodioecious population with such a determination of sex and compare these conditions with those obtained when the determination of sex is nuclear.

\section{Model}

The model is similar to the one described in Gouyon et al. (1991) which was based on the situation encountered in Plantago lanceolata (Van Damme, 1983). There are two cytotypes. Corresponding to each cytotype $(C 1, C 2)$, there exist nuclear loci $(1,2)$ which control restoration of male fertility (i.e. pollen production). Being male or hermaphrodite can be controlled by different restorer alleles or by modifiers of sex allocation at other loci. We thus have considered two possible models for the control of sex. In the two-locus model (Table 1), both loci $(1,2)$ have three alleles: one allele that does not restore male fertility (usually called maintainer alleles: $r 1, r 2$ ) and two alleles that restore male fertility. One restorer allele makes an individual hermaphroditic $(R 1, R 2)$, the other makes complete males $\left(R^{\prime} 1, R^{\prime} 2\right)$. In the three-locus model (Table 2), each restorer locus $(1,2)$ has a maintainer allele $(r 1, r 2)$ and a restorer allele $(R 1, R 2)$. Individuals restored for male fertility are hermaphrodite or male depending on their genotype at a third nuclear locus $(M / m)$. We assume that the restorer alleles are dominant over the maintainer or female alleles, which is the most commonly observed case (Kaul, 1988, p.121). Most calculations were made with the male alleles dominant over the hermaphroditic alleles, but we also calculated the reverse to check if it influences the results. In both models the loci are assumed to be unlinked. The notation is the same as in Charnov et al. (1976): $\beta$ is the relative female fertility of hermaphrodites compared with females and $\alpha$ is the relative male fertility of hermaphrodites compared with males. Following the standard resource allocation theory, unisexual individuals are better in their specific function than hermaphrodites. The parameters $\alpha$ and $\beta$ thus vary between zero and one. Restorer alleles are assumed to have a pleiotropic deleterious effect (Charlesworth, 1981; Delannay et al., 1981; Frank, 1989). This deleterious effect, or cost, is denoted by $d$ and is the diminution in fertility of individuals bearing a restorer allele compared with individuals bearing only the maintainer allele at the corresponding locus. This cost can affect 

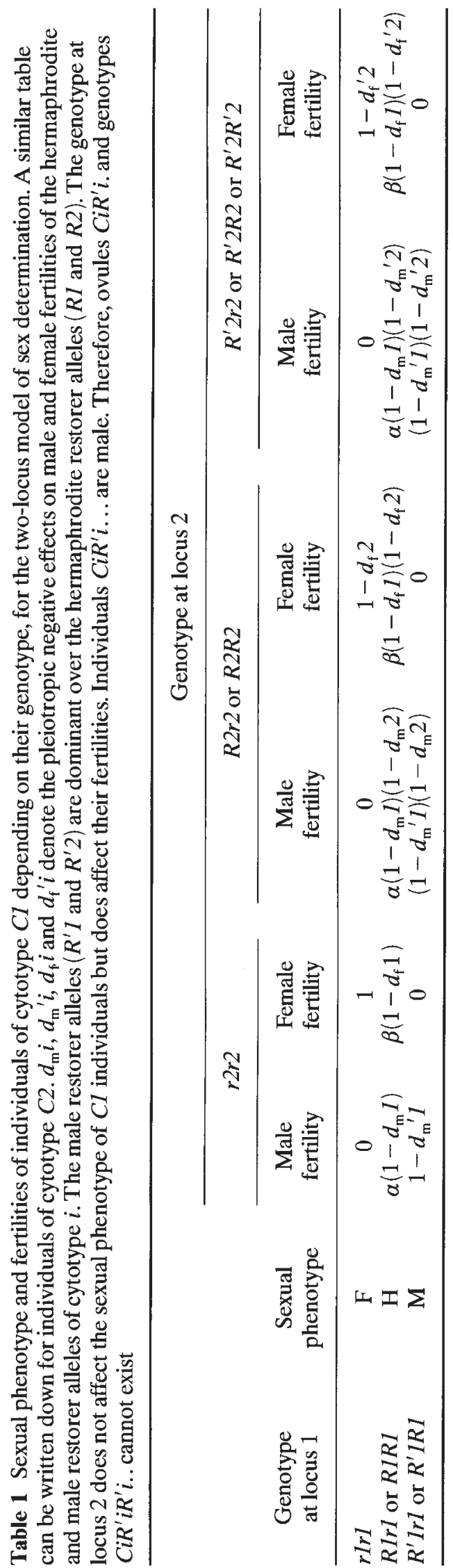

female fertility $\left(d_{\mathrm{f}}\right)$ or male fertility $\left(d_{\mathrm{m}}\right)$. In the twolocus model, the hermaphrodite restorer allele and the male restorer allele need not have the same cost (Table 1). In the three-locus model, only restorer alleles have cost (loci 1 and 2) and the male allele at the third locus has no effect on females. The fertilities of the different genotypes are given in Tables 1 and 2.

The cytotype is assumed to be exclusively maternally transmitted. Hermaphrodites are assumed not to self-fertilize, so that gametes combine at random. The dominance assumed for the sexual phenotypic effect of alleles is also applied to their deleterious effects (see Tables 1 and 2). We present the results obtained when the parameter values are the same for both cytotypes and when the male and hermaphrodite restorer alleles have the same cost, so that the differences between individuals are restricted to their sexual phenotype. The model thus has four parameters: $\alpha, \beta, d_{\mathrm{m}}$ and $d_{\mathrm{f}}$, which are constant for each calculation.

The cost of the restorer alleles was arbitrarily set at 5 per cent (low cost) and 20 per cent (high cost), on one or both fertilities. The recursions describing change in genotype frequencies are given in the Appendix. Starting with arbitrary frequencies of female and hermaphrodite genotypes, we first let the population evolve until an equilibrium was reached to find the range of $\beta$ values for which nuclear-cytoplasmic gynodioecy is obtained. The equilibrium was defined by a change in genotype frequencies of less than $10^{-4}$ over 100 generations. Values of $\beta$ differing by steps of 0.01 were used to find the limit for gynodioecy. Gynodioecious populations contain both cytoplasmic types $(C 1, C 2)$ and riri, riRi, RiRi genotypes at both restorer loci. Then, for different values of $\beta$, males were introduced at low frequency after the gynodioecious equilibrium was reached. For the two-locus model the genotypes $C 1 R^{\prime} 1 R 1 R 2 r 2$ and $C 2 R 1 r 1 R^{\prime} 2 R 2$ were introduced at a frequency of 0.005 each. We also carried out calculations introducing first the male restorer active in one cytotype $\left(R^{\prime} 1\right)$ and introducing the second male restorer $\left(R^{\prime} 2\right)$ only after the new equilibrium was reached. For the three-locus model, the genotype $C 1 R 1 r 1 R 2 \mathrm{r} 2 \mathrm{Mm}$ was introduced at a frequency of 0.005 . Using a step of 0.01 for $\alpha$, we found the range of $\alpha$ for which males increase in frequency when rare $(\alpha<\alpha 1)$ and the range of $\alpha$ for which males increase in frequency and completely displace the hermaphrodites $(\alpha<\alpha 2)$. Again, the final state corresponds to a change in genotype frequencies of less than $10^{-4}$ over 100 generations. We verified that the final state was a stable equilibrium by carring out the reverse calculations, i.e. starting with a dioecious population and introducing hermaphrodites at low frequency. The final state was usually approached 
Table 2 Sexual phenotype and fertilities of individuals of cytotype $C l$ depending on their genotype for the three-locus model of sex determination. A similar table can be written down for individuals of cytotype $C 2$. Notations are the same as in Table 1 . The male allele $(M)$ is dominant over the hermaphrodite allele $(m)$. The genotype at locus 2 does not affect the sexual phenotype of $C 1$ individuals but does affect their fertilities

\begin{tabular}{|c|c|c|c|c|c|c|}
\hline \multirow[b]{3}{*}{$\begin{array}{l}\text { Genotype } \\
\text { at locus } 1\end{array}$} & \multirow[b]{3}{*}{$\begin{array}{l}\text { Genotype } \\
\text { at locus } 3\end{array}$} & \multirow[b]{3}{*}{$\begin{array}{c}\text { Sexual } \\
\text { phenotype }\end{array}$} & \multicolumn{4}{|c|}{ Genotype at locus 2} \\
\hline & & & \multicolumn{2}{|c|}{$r 2 r 2$} & \multicolumn{2}{|c|}{$R 2 r 2$ or $R 2 R 2$} \\
\hline & & & $\begin{array}{l}\text { Male } \\
\text { fertility }\end{array}$ & $\begin{array}{l}\text { Female } \\
\text { fertility }\end{array}$ & $\begin{array}{l}\text { Male } \\
\text { fertility }\end{array}$ & $\begin{array}{l}\text { Female } \\
\text { fertility }\end{array}$ \\
\hline \multirow[t]{2}{*}{$r l r 1$} & $m m$ & $\mathrm{~F}$ & 0 & 1 & 0 & $1-d_{\mathrm{f}} 2$ \\
\hline & $M m$ or $M M$ & $\mathrm{~F}$ & 0 & 1 & 0 & $1-d_{\mathrm{f}} 2$ \\
\hline \multirow[t]{2}{*}{$R 1 r 1$ or $R I R 1$} & $m m$ & $\mathrm{H}$ & $\alpha\left(1-d_{\mathrm{m}} l\right)$ & $\beta\left(1-d_{\mathrm{f}} l\right)$ & $\alpha\left(1-d_{\mathrm{m}} 1\right)\left(1-d_{\mathrm{m}} 2\right)$ & $\beta\left(1-d_{\mathrm{f}} 1\right)\left(1-d_{f} 2\right)$ \\
\hline & $M m$ or $M M$ & M & $1-d_{\mathrm{m}} 1$ & 0 & $\left(1-d_{\mathrm{m}} 1\right)\left(1-d_{\mathrm{m}} 2\right)$ & 0 \\
\hline
\end{tabular}

Table 3 Frequency of females in gynodioecious populations, depending on the relative female fertility of hermaphrodites compared with females $(\beta)$, when the control of sex is nuclear or nuclear-cytoplasmic. When the control of sex is nuclear-cytoplasmic, the frequency of the restorer allele $R i$ at locus $i(i=1$ or 2$)$ is indicated in parentheses. The frequency of each cytotype is 0.5

\begin{tabular}{|c|c|c|c|c|c|}
\hline \multirow[b]{3}{*}{$\beta$} & \multicolumn{5}{|c|}{ Control of sex } \\
\hline & \multirow[b]{2}{*}{ Nuclear } & \multicolumn{4}{|c|}{ Nuclear-cytoplasmic } \\
\hline & & $\begin{array}{c}d_{\mathrm{m}}=0.05 \\
d_{\mathrm{f}}=0\end{array}$ & $\begin{array}{c}d_{\mathrm{m}}=0.05 \\
d_{\mathrm{f}}=0.05\end{array}$ & $\begin{array}{c}d_{\mathrm{m}}=0.20 \\
d_{\mathrm{f}}=0\end{array}$ & $\begin{array}{l}d_{\mathrm{m}}=0.20 \\
d_{\mathrm{f}}=0.20\end{array}$ \\
\hline 0.2 & 0.375 & $\begin{array}{c}0.383 \dagger \\
(0.452)\end{array}$ & $\begin{array}{c}0.400 \\
(0.436)\end{array}$ & $\begin{array}{c}0.415 \\
(0.426)\end{array}$ & $\begin{array}{c}0.489 \\
(0.358)\end{array}$ \\
\hline 0.4 & 0.167 & $\begin{array}{c}0.179 \\
(0.620)\end{array}$ & $\begin{array}{c}0.218 \\
(0.578)\end{array}$ & $\begin{array}{c}0.228 \\
(0.570)\end{array}$ & $\begin{array}{r}0.378 \ddagger \\
(0.432)\end{array}$ \\
\hline 0.5 & 0 & $\begin{array}{c}0.021 \\
(0.862)\end{array}$ & $\begin{array}{c}0.082 \\
(0.736)\end{array}$ & $\begin{array}{c}0.090 \\
(0.722)\end{array}$ & $\begin{array}{c}0.306 \\
(0.486)\end{array}$ \\
\hline 0.6 & - & - & - & - & $\begin{array}{c}0.219 \\
(0.560)\end{array}$ \\
\hline 0.8 & - & - & - & - & $\begin{array}{c}0.020 \\
(0.862)\end{array}$ \\
\hline
\end{tabular}

A - means that females are not maintained under these conditions.

$\dagger$ and $\ddagger$ The two cases discussed in the text.

rapidly (less than 100 generations) except near the limit values of $\alpha$.

We verified that the program gave the same results as analytical calculations for nuclear determination of sex, when all the genotypes of one cytotype were set to zero at the beginning of the calculations.

\section{Results}

\section{Nuclear-cytoplasmic polymorphism}

As already explained in previous papers (Charlesworth, 1981; Delannay et al., 1981; Gouyon et al.,
1991), the cost of restorer alleles allows for the maintenance of joint polymorphism, i.e. polymorphism for the cytotypes and for the restorer loci, in gynodioecious reproductive systems. We found here that this also holds for other reproductive systems whenever the maintainer alleles are not lost, i.e. when the females are not eliminated. The joint polymorphism is thus maintained under gynodioecy, dioecy and trioecy (coexistence of females, males and hermaphrodites). The mechanism responsible for the maintenance of this polymorphism is the same as the one detailed in Gouyon et al. (1991) for gynodioecy. 


\section{Conditions for nuclear-cytoplasmic gynodioecy}

Females are maintained or not depending on the relative fertility of hermaphrodites compared with females $(\beta)$ and the cost of restoration. As $\beta$ increases, the frequency of females decreases. The calculations are deterministic (without drift) and a very low frequency of females allows the maintenance of joint polymorphism. The value of $\beta$ above which the female frequency is less than 0.1 per cent is considered as the limit for gynodioecy. When the cost is 5 per cent and on male function only, the limiting $\beta$ is 0.51 ; when it is on both fertilities, the threshold $\beta$ is 0.55 . When the cost is 20 per cent and on male function only, the threshold $\beta$ is 0.57 ; when it is on both fertilities, it is 0.82 . The limit of $\beta$ for the maintenance of females under nuclear sex determination is 0.5 (Lewis, 1941). Examples of frequencies of females in gynodioecious populations with a nuclear or a nuclear-cytoplasmic determination of sex are given in Table 3.

\section{Conditions for the evolution of dioecy}

For some parameter values males increase in frequency but do not eliminate the hermaphrodites. The rate of increase of the male alleles at the beginning of the process depends on whether the male alleles are dominant over the hermaphrodite alleles, or the reverse, but the final result is never different. The threshold of the male fertility of hermaphrodites compared with males under which a rare male phenotype increases in frequency is denoted by $\alpha 1$. The value for which males increase in frequency and completely eliminate the hermaphrodites is denoted by $\alpha 2$. These values are given in Table 4 for the two genetic models for maleness. In every case, the values $(\alpha 1$ and $\alpha 2)$ are equal to or higher than the corresponding values for a nuclear sex determination. This means that males both increase and invade under less restrictive conditions with nuclear-cytoplasmic control of sex. The difference in conditions is, however, usually quite small. It becomes larger as the cost of restorer alleles increases and/or affects both fertilities. The comparison of Tables 3 and 4 (for example cases $\dagger$ and $\mp$ ) shows that the change on the threshold $\alpha$ is linked to the increase in female frequency compared with nuclear control of sex. It does not depend on whether the cytotypes are more or less restored (the frequencies of the restorer alleles are similar in the two cases).

The joint polymorphism is maintained under dioecy, i.e. both $C 1$ and $C 2$ as well as the polymorphism at the nuclear restorer loci are maintained. In such dioecious systems, the frequency of females always exceeds 50

Table 4 Limit on the relative male fertility of hermaphrodites compared with males $(\alpha)$ for the increase of males in the population: if $\alpha \leq \alpha l$ then males, if rare, increase in the population; if $\alpha \leq \alpha 2$ then hermaphrodites are eliminated from the population, i.e. $\alpha 2$ is the threshold for dioecy. If $\alpha 2<\alpha \leq \alpha 1$ males and hermaphrodites coexist, i.e. the reproductive system is trioecy (except in the two nuclear cases denoted by $\S$ in which females are not present). For each set of parameters, the first line gives the results for the two-locus model and the second line the results for the three-locus model

\begin{tabular}{|c|c|c|c|c|c|c|c|c|c|c|}
\hline \multirow[b]{4}{*}{$\beta$} & \multicolumn{10}{|c|}{ Control of sex } \\
\hline & \multirow{2}{*}{\multicolumn{2}{|c|}{ Nuclear }} & \multicolumn{8}{|c|}{ Nuclear-cytoplasmic } \\
\hline & & & \multicolumn{2}{|c|}{$\begin{array}{c}d_{\mathrm{m}}=0.05 \\
d_{\mathrm{f}}=0\end{array}$} & \multicolumn{2}{|c|}{$\begin{array}{l}d_{\mathrm{m}}=0.05 \\
d_{\mathrm{f}}=0.05\end{array}$} & \multicolumn{2}{|c|}{$\begin{array}{c}d_{\mathrm{m}}=0.20 \\
d_{\mathrm{f}}=0\end{array}$} & \multicolumn{2}{|c|}{$\begin{array}{c}d_{\mathrm{m}}=0.20 \\
d_{\mathrm{f}}=0.20\end{array}$} \\
\hline & $\alpha 1$ & $\alpha 2$ & $\alpha 1$ & $\alpha 2$ & $\alpha 1$ & $\alpha 2$ & $\alpha 1$ & $\alpha 2$ & $\alpha 1$ & $\alpha 2$ \\
\hline \multirow[t]{2}{*}{0.2} & 0.80 & 0.80 & 0.80 & 0.80 & 0.81 & 0.81 & 0.81 & 0.81 & 0.85 & 0.85 \\
\hline & & & 0.80 & 0.80 & 0.81 & 0.81 & 0.81 & 0.81 & 0.86 & 0.86 \\
\hline \multirow[t]{2}{*}{0.4} & 0.60 & 0.60 & 0.60 & 0.60 & 0.63 & 0.62 & 0.62 & 0.62 & 0.72 & 0.71 \\
\hline & & & 0.60 & 0.60 & 0.63 & 0.63 & 0.63 & 0.63 & 0.73 & 0.73 \\
\hline \multirow[t]{2}{*}{0.5} & 0.50 & 0.50 & 0.51 & 0.50 & 0.54 & 0.53 & 0.54 & 0.52 & 0.65 & 0.64 \\
\hline & & & 0.51 & 0.50 & 0.54 & 0.54 & 0.54 & 0.54 & 0.66 & 0.66 \\
\hline \multirow[t]{2}{*}{0.6} & 0.50 & $0.40 \S$ & & & & & & & 0.59 & 0.57 \\
\hline & & & & & & & & & 0.60 & 0.60 \\
\hline \multirow[t]{2}{*}{0.8} & 0.50 & $0.20 \S$ & & & & & & & 0.50 & 0.42 \\
\hline & & & & & & & & & 0.50 & 0.46 \\
\hline
\end{tabular}


per cent, usually slightly. For the four cases of Table 4 , the frequency of females in dioecious populations is $0.506,0.513,0.531$ and 0.567 , respectively.

\section{Conditions for trioecy}

The values of $\alpha 1$ and $\alpha 2$ are not always the same, unlike the nuclear case. This means that for some values of the relative fertility of hermaphrodites compared with males $(\alpha 2<\alpha \leq \alpha 1)$, rare males increase in frequency but do not eliminate the hermaphrodites, i.e. trioecy is the reproductive system. These trioecious systems are stable: the sex ratio at equilibrium is the same whether the males or the hermaphrodites are the rare type at the beginning of the calculation. With the three-locus model of sex control, each sexual phenotype has the same frequency in $C 1$ and $C 2$. For the twolocus model, as the introduction of the male restorer alleles of both cytotypes at the same time is quite unrealistic, we have verified that trioecy evolves when one of the male restorer alleles is introduced first. The conditions are exactly the same as those already found. When $\alpha>\alpha 1$, none of the male restorer alleles increases. When $\alpha \leq \alpha 2$, both male restorer alleles invade. When $\alpha 2<\alpha \leq \alpha 1$, the first male restorer allele introduced invades the corresponding cytotype: the population is then composed of a dioecious cytotype and a gynodioecious cytotype; the second male restorer allele does not increase. The only exception is that when $\alpha<0.5$ (e.g. in the last case of Table 4) the second male restorer allele increases but does not eliminate the corresponding hermaphrodite restorer allele: one cytotype is dioecious and the other one is trioecious or androdioecious. Thus, with the two-locus control of sex, trioecy can also be the reproductive system but not all sexual phenotypes are found in each cytotype.

\section{Discussion}

We show here that dioecy evolves in less restrictive conditions when the control of sex is nuclear-cytoplasmic compared with when the sex determination is nuclear. Another noticeable difference is that trioecious reproductive systems can be stable. The cytoplasmic polymorphism is maintained under these reproductive systems.

The results presented here were obtained by comparing, in each calculation, male individuals, female individuals and one kind of hermaphrodite individual (i.e. characterized by fixed relative female and male fertilities). The results thus give us the reproductive system obtained when hermaphrodites in the population have a fixed sexual allocation and are in competition with wholly male individuals. Selfing in hermaphrodites was not considered in those calculations because we wanted to focus on the consequences of a change in the genetic control of sex. Selfing changes the conditions for the evolution of dioecy under any genetic control of sex but there is no reason to believe that selfing would change the direction of the effects of the sex determination. Compared with the stable reproductive system obtained when the control of sex is nuclear, the nuclear-cytoplasmic models more often give gynodioecy, dioecy and trioecy at the expense of hermaphroditism or androdioecy. Reproductive systems with females are thus obtained in a wider range of conditions, as could have been predicted. The important result here is that the cytoplasmic genes cause an increase in female frequency compared with purely nuclear control of sex and that, despite the fact that cytoplasmic genes play a part in the sex determination, this can select for maleness. This is proven by the fact that reproductive systems with males, dioecy or trioecy sometimes replace other reproductive systems, including gynodioecy. Furthermore, not only can male-sterile cytoplasmic mutations result in selection for females and afterwards males but nuclear-cytoplasmic polymorphism can be maintained under these new reproductive systems (dioecy and trioecy). It is thus possible that nuclear-cytoplasmic determination acts not only as a transient stage as has been previously proposed (Delannay et al., 1981; Gouyon \& Couvet, 1985) but can also be maintained during and after the evolution of dioecious reproductive systems.

If the alleles restoring male fertility have only a slight negative pleiotropic effect on fertility, the range of values in which dioecy is the stable reproductive system under nuclear-cytoplasmic control of sex is only a little larger than when the control of sex is nuclear. This nevertheless proves that dioecy can evolve from nuclear-cytoplasmic gynodioecy, contrary to the common belief (Ross, 1978; but see Maurice et al., 1993). Two points can be made. Firstly, the evolution of dioecy is not favoured when the cytotype(s) responsible for male sterility is (are) not restored, i.e. when the control of sex is strictly cytoplasmic (Charlesworth, 1989; Maurice et al., 1993). We showed here that once the cytotypes are restored, the selection on males does not depend on the extent to which the cytotypes are restored (frequency of restorer alleles) but does depend on the increase in female frequency. There is thus a discontinuity between a purely cytoplasmic control of sex and a nuclear-cytoplasmic control. Secondly, if we compare populations with individuals having the same characteristics (relative fertilities), nuclear-cytoplasmic sex determination favours the evolution of dioecy compared with nuclear deter- 
mination. But if we compare populations with the same frequency of females, nuclear determination is more favourable to the evolution of males than a nuclear-cytoplasmic model (Table 5); one must nevertheless remember that females need to have a higher relative fertility to reach a given frequency if the control of sex is nuclear.

Atlan et al. (1991) have found variability for sex allocation among hermaphrodites of the gynodioecious species Thymus vulgaris, which is known to have nuclear-cytoplasmic sex determination (Belhassen et al., 1991). It is not known whether these differences result from different restorer alleles or from modifier genes acting on restored individuals. We thus considered both possibilities for the control of maleness: the two-locus model corresponds to the 'different restorers' hypothesis and the three-locus model corresponds to the 'modifiers' hypothesis. The results are very similar between the two models. Males are a little more easily selected in the three-locus model and trioecy more rarely obtained.

Few studies have been carried out on the evolution of dioecy under nuclear-cytoplasmic sex determination. Gregorius \& Ross (1987) studied the evolution of dioecy in a model with two cytotypes and one nuclear locus with two alleles in which the nuclear allelic difference produces dioecy in one cytotype and hermaphrodism or gynodioecy in the other cytotype. They showed that dioecy can evolve by loss of the nondioecious cytotype. Their results cannot be compared with ours because in their model the reproductive system obtained is the result of the competition between the two cytotypes whereas in our model it is the result of the competition between hermaphrodite and male genotypes in each cytotype. Maurice et al. (1993) studied the evolution of dioecy in a two-cytotype-twoloci model based on the first model proposed for nuclear-cytoplasmic gynodioecy (Charlesworth, 1981; Delannay et al., 1981), i.e. all individuals of one cytotype are male-fertile and individuals of the other cytotype are male-sterile (female) or male-fertile depending on the genotype at the nuclear restoration locus. In their model, as in the model presented here, both cytotypes can yield hermaphrodite and male individuals depending on the nuclear genotypes. They showed that male individuals, or a more male-biased sexual allocation in hermaphrodites, can evolve, but if selection towards maleness is too strong the cytoplasmic polymorphism is lost during the evolution of dioecy. The fact that nuclear-cytoplasmic gynodioecy can allow and even facilitate the evolution of dioecy thus seems to have some general value but whether that mode of sex control is retained in the new reproductive system depends on the particular sex determination system.
Table 5 Limit on the relative male fertility of hermaphrodites $(\alpha 2)$ for the evolution of dioecy, for nuclear and nuclear-cytoplasmic sex determination models and for a given frequency of females in the gynodioecious population $(F)$. For each model, the frequency of females in the population and the relative female fertility of hermaphrodites $(\beta)$ are strictly inter-related. For the nuclear model, the relation is: $\beta=(1-2 F) / 2(1-F)$ and the threshold value of $\alpha$ for the evolution of dioecy is given by the relation $\alpha+\beta=1$ (Charnov et al., 1976). For the nuclear-cytoplasmic model, the calculations are those for the three-locus model

\begin{tabular}{|c|c|c|c|c|}
\hline \multirow[b]{3}{*}{$F$} & \multicolumn{4}{|c|}{ Control of sex } \\
\hline & \multicolumn{2}{|c|}{ Nuclear } & \multicolumn{2}{|c|}{$\begin{array}{c}\text { Nuclear-cytoplasmic } \\
d_{\mathrm{m}}=0.20 d_{\mathrm{f}}=0\end{array}$} \\
\hline & $\beta$ & $\alpha 2$ & $\beta$ & $\alpha 2$ \\
\hline 0.415 & 0.15 & 0.85 & 0.20 & 0.81 \\
\hline 0.228 & 0.35 & 0.65 & 0.40 & 0.63 \\
\hline \multirow[t]{2}{*}{0.090} & 0.45 & 0.55 & 0.50 & 0.54 \\
\hline & \multicolumn{2}{|c|}{ Nuclear } & \multicolumn{2}{|c|}{$\begin{array}{c}\text { Nuclear-cytoplasmic } \\
d_{\mathrm{m}}=d_{\mathrm{f}}=0.20\end{array}$} \\
\hline$F$ & $\beta$ & $\alpha 2$ & $\beta$ & $\alpha 2$ \\
\hline 0.489 & 0.02 & 0.98 & 0.20 & 0.86 \\
\hline 0.378 & 0.20 & 0.80 & 0.40 & 0.73 \\
\hline 0.219 & 0.36 & 0.64 & 0.60 & 0.60 \\
\hline
\end{tabular}

In this model we have considered only selection of males in gynodioecious populations with one kind of hermaphrodite. In reality, whether completely male individuals or hermaphrodites that are more male are selected depends on: (1) whether female-sterile mutations or mutations that only slightly modify the male/ female allocation of hermaphrodites arise more easily, and (2) if slight modifications of the sexual allocation are the more common, the sexual allocation selected in hermaphrodites depends on the set of all relative fertilities possible for the hermaphrodites and on the characteristics of sex determination, including the characteristics of cytotypes and the deleterious effects of restorers.

Nuclear-cytoplasmic interactions allow females and sometimes males or more male-biased hermaphrodites to be maintained. This can allow selection to act on these new sexual phenotypes (Gouyon \& Couvet, 1985) and/or change the outcrossing rate of the population. If this occurs, a new reproductive system could be stable even if the nuclear-cytoplasmic polymorphism is finally lost. The consequences of nuclear-cytoplasmic interactions on reproductive systems are thus probably even more important than is shown here. 


\section{References}

ATLAN, A., GOUYON, P.-H., FOURNIAL. T., POMENTE, D. AND COUVET, D. 1991. Sex allocation in an hermaphroditic plant: the case of gynodioecy in Thymus vulgaris L. J. Evol. Biol., 5, 189-203.

BAKER, H. G. 1963. Evolutionary mechanisms in pollination biology. Science, 139, 877-883.

BELHASSEN, E., DOMMEE, B., ATLAN, A., GOUYON, P.-H., POMENTE, D., ASSOUAD, M. W. AND CouvET, D. 1991. Complex determination of male sterility in Thymus vulgaris L.: genetic and molecular analysis. Theor. Appl. Genet., 82, 137-143.

CHARLESWORTH, B. AND CHARLESWORTH, D. 1978. A model for the evolution of dioecy and gynodioecy. Am. Nat., 112, 975-997.

CHARLESWORTH, D. 1981. A further study of the problem of the maintenance of females in gynodioecious species. Heredity, 46, 27-39.

CHARLESWORTH, D. 1989. Allocation to male and female function in hermaphrodites, in sexually polymorphic populations. J. Theor. Biol., 139, 327-342.

CHARNOV, E. L., MAYNARD SMITH, J. AND BULL, J. J. 1976. Why be an hermaphrodite? Nature, 236, 125-127.

DELANNAY, X., GOUYON, P.-H. AND VALDEYRON, G. 1981. Mathematical study of the evolution of gynodioecy with cytoplasmic inheritance under the effect of a nuclear restorer gene. Genetics, 99, 169-181.

DOMMEE, B., ASSOUAD, M. W. AND VALDEYRON, G. 1978. Natural selection and gynodioecy in Thymus vulgaris L. Bot. J. Linn. Soc., 77, 17-28.

FRANK, S. A. 1989. The evolutionary dynamics of cytoplasmic male sterility. Am. Nat., 133, 345-376.

GOUYON, P. H. AND COUVET, D. 1985. Selfish cytoplasm and adaptation: variations in the reproductive system of thyme. In: Haeck, J. and Woldendorp, J. W. (eds) Structure and Functioning of Plant Populations/2, pp. 299-319. North-Holland, New York.

GOUYON, P.-H., VICHOT, F. AND VAN DAMME, J. M. M. 1991. Nuclear-cytoplasmic male sterility: single-point equilibria versus limit cycles. Am. Nat., 137, 498-514.

GREGORIUS, H.-R. AND ROSS, M. D. 1987. Selection with gene-cytoplasm interactions. III. Evolution of dioecy. Evol. Theory, 8, 87-89.

GREGORIUS, H.-R., ROSS, M. D. AND GILLET, E. M. 1983. Selection in plant populations of effectively infinite size. V. Biallelic models of trioecy. Genetics, 103, 529-544.

KAUL, M. L. H. 1988. Male Sterility in Higher Plants. Monographs on Theoretical and Applied Genetics, vol. 4. Springer-Verlag, Berlin.

KHEYR-POUR, A. 1980. Nucleo-cytoplasmic polymorphism for male sterility in Origanum vulgare L. J. Hered., 71 , 253-260.

LEWIS, D. 1941. Male sterility in natural populations of hermaphrodite plants. New Phytol., 40, 56-63.

LLOYD, D. G. 1974. Theoretical sex ratios of dioecious and gynodioecious angiosperms. Heredity, 32, 11-34.

MAURICE, S., CHARLESWORTH, D., DESFEUX, C., COUVET, D. AND GOUYON, P.-H. 1993. The evolution of gender in hermaphrodites of gynodioecious populations with nucleo-cytoplasmic male-sterility. Proc. R. Soc. B., 251, 253-261.
Ross, M. D. 1978. The evolution of gynodioecy and subdioecy. Evolution, 32, 174-188.

ROSS, M. D. AND GREgorIUS, H.-R. 1985. Selection with gene-cytoplasm interactions. II. Maintenance of gynodioecy. Genetics, 109, 427-439.

THOMSON, J. D. AND BARRET, S. C. H. 1981. Selection for outcrossing, sexual selection and the evolution of dioecy in plants. Am. Nat., 118, 443-449.

THOMSON, J. D. AND BRUNET, J. 1990. Hypotheses for the evolution of dioecy in seed plants. Trends Ecol. Evol., 5, 11-16.

VAN DAMME, J. M. M. 1983. Gynodioecy in Plantago lanceolata L. II. Inheritance of three male sterility types. Heredity, 50, 253-273.

VAN DAMME, J. M. M. 1985. Why are so many Plantago species gynodioecious? In: Haeck, J. and Woldendorp, J. W. (eds) Structure and Functioning of Plant Populations/2, pp. 241-249. North-Holland, New York.

WILlSON, M. F. 1979. Sexual selection in plants. Am. Nat., 113, 777-790.

WERREN, J. H. 1987. The coevolution of autosomal and cytoplasmic sex ratio factors. J. Theor. Biol., 124, 317-334.

\section{Appendix: evolution of genotype frequencies}

\section{Two-locus model for the control of sex}

Notations are the same as in the text and in Table 1. Deleterious effects of restorer alleles have the same value for $R 1$ and $R 2\left(d_{\mathrm{m}} 1=d_{\mathrm{m}} 2=d_{\mathrm{m}}, \mathrm{d}_{\mathrm{f}} 1=\mathrm{d}_{\mathrm{f}} 2=\mathrm{d}_{\mathrm{f}}\right)$ and for $R^{\prime} 1$ and $R^{\prime} 2\left(d_{\mathrm{m}}{ }^{\prime} 1=d_{\mathrm{m}}{ }^{\prime} 2=d_{\mathrm{m}}{ }^{\prime}, d_{\mathrm{f}}{ }^{\prime} 1=d_{\mathrm{f}}{ }^{\prime} 2=d_{\mathrm{f}}{ }^{\prime}\right)$.

The relative frequencies of genotypes in ovules at the next generation are:

for ovules C1r1r2: [C1r1r1r2r2 $+\frac{1}{2}\left(1-d_{\mathrm{f}}\right)$ C1r1r1R2r2

$\left.+\frac{1}{2}\left(1-d_{\mathrm{f}}{ }^{\prime}\right) C 1 r 1 r 1 R^{\prime} 2 r 2\right]+\beta \cdot \frac{1}{2}\left(1-d_{\mathrm{f}}\right)[C 1 R 1 r 1 r 2 r 2$

$\left.+\frac{1}{2}\left(1-d_{\mathrm{f}}\right) C 1 R 1 r 1 R 2 r 2+\frac{1}{2}\left(1-d_{\mathrm{f}}{ }^{\prime}\right) C 1 R 1 r 1 R^{\prime} 2 r 2\right]$;

for ovules $C 1 R 1 R^{\prime} 2: \beta\left(1-d_{\mathrm{f}}\right)\left(1-d_{\mathrm{f}}{ }^{\prime}\right)\left[{ }_{4}^{1} . C 1 R 1 r 1 R^{\prime} 2 r 2\right.$

$+\frac{1}{4} . C 1 R 1 r 1 R^{\prime} 2 R 2+\frac{1}{2} . C 1 R 1 r 1 R^{\prime} 2 R^{\prime} 2$

$+\frac{1}{2} . C 1 R 1 R 1 R^{\prime} 2 r 2+\frac{1}{2} . C 1 R 1 R 1 R^{\prime} 2 R 2$

$+C 1 R 1 R 1 R^{\prime} 2 R^{\prime} 2$ ]; etc.

Ovules $C 1 R^{\prime} 1$. and $C 2 R^{\prime} 2$. cannot exist because the individuals $C 1 R^{\prime} 1 \ldots$ and $C 2 \ldots R^{\prime} 2$. are male. That implies that genotypes $C i R^{\prime} i R^{\prime} i$.. do not exist either.

The relative frequencies of genotypes in pollen at the next generation are:

for pollen $r 1 r 2: \alpha \cdot \frac{1}{2}\left(1-d_{\mathrm{m}}\right)[$ CiRiririrj

$+\frac{1}{2}\left(1-d_{\mathrm{m}}\right)$ CiRiriRjirj $+\frac{1}{2}\left(1-d_{\mathrm{m}}{ }^{\prime}\right)$ CiRiriR' $\left.^{\prime} j \mathrm{rj}\right]$

$+\frac{1}{2}\left(1-d_{\mathrm{m}}{ }^{\prime}\right)\left[\right.$ CiR' $^{\prime}$ iririrj $+\frac{1}{2}\left(1-d_{\mathrm{m}}\right)$ CiR $^{\prime}$ iriRjirj

$\left.+\frac{1}{2}\left(1-d_{\mathrm{m}}{ }^{\prime}\right) C i R^{\prime} i r i R^{\prime} j r j\right]$, with $(i, j)=(1,2)$ and $(2,1)$;

for pollen $R 1 R^{\prime} 2$ : $\alpha\left(1-d_{\mathrm{m}}{ }^{\prime}\right)\left(1-d_{m}\right)\left[{ }_{4}^{1} C 1 R 1 r 1 R^{\prime} 2 r 2\right.$

$+{ }_{4}^{1} C 1 R 1 r 1 R^{\prime} 2 R 2+\frac{1}{2} . C 1 R 1 r 1 R^{\prime} 2 R^{\prime} 2+\frac{1}{2} . C 1 R 1 R 1 R^{\prime} 2 r 2$

$+\frac{1}{2}$. CIR1R1R' $\left.2 R 2+C 1 R 1 R 1 R^{\prime} 2 R^{\prime} 2\right]$

$+\frac{1}{2}\left(1-d_{\mathrm{m}}\right)^{2}\left[\frac{1}{2} . C 1 R^{\prime} 1 R 1 R^{\prime} 2 r 2+\frac{1}{2} . C 1 R^{\prime} 1 R 1 R^{\prime} 2 R 2\right.$

$\left.+C 1 R^{\prime} 1 R 1 R^{\prime} 2 R^{\prime} 2\right]+\left(1-d_{\mathrm{m}}\right)\left(1-d_{\mathrm{m}}{ }^{\prime}\right)\left[\frac{1}{4} . C 2 R 1 r 1 R^{\prime} 2 r^{\prime}\right.$

$+\frac{1}{4} . C 2 R 1 r 1 R^{\prime} 2 R 2+\frac{1}{2} . C 2 R 1 R 1 R^{\prime} 2 r 2$

$\left.+\frac{1}{2} . C 2 R 1 R 1 R^{\prime} 2 R 2\right]+\frac{1}{2}\left(1-d_{\mathrm{m}}\right)^{\prime}\left[\frac{1}{2} . C 2 R^{\prime} 1 R 1 R^{\prime} 2 r 2\right.$

$\left.+\frac{1}{2} . C 2 R^{\prime} 1 R 1 R^{\prime} 2 R 2\right]$; etc. 
The frequencies of genotypes at the next generation are obtained by multiplying the frequencies of ovules and pollen and dividing them by the total ovule and pollen productions:

$$
\begin{aligned}
& \text { total ovules }=\left[\text { Ciriririrj }+\left(1-d_{\mathrm{f}}\right)[\text { CiririRjrj }+ \text { CiririRjRj }]\right. \\
& \left.+\left(1-d_{\mathrm{f}}{ }^{\prime}\right) \text { CiririR }{ }^{\prime} j .\right]+\beta\left(1-d_{\mathrm{f}}\right)[\text { CiRiririrj } \\
& + \text { CiRiRirjrj }+\left(1-d_{\mathrm{f}}\right)[\text { CiRiriRjrj+CiRiriRjRj } \\
& + \text { CiRiRiRjrj+ CiRiRiRjRj] }+\left(1-d_{\mathrm{f}}{ }^{\prime}\right)\left[\text { CiRiriR }^{\prime} j\right. \text {. } \\
& + \text { CiRiRiR'j.]]; }
\end{aligned}
$$$$
\text { with }(i, j)=(1,2) \text { and }(2,1) \text {; }
$$$$
\text { total pollen }=\alpha\left(1-d_{\mathrm{m}}\right)[\text { CiRirirjirj }+ \text { CiRiRirjrj }
$$$$
+\left(1-d_{\mathrm{m}}\right)[\text { CiRiriRjrj }+ \text { CiRiriRjRj }+ \text { CiRiRiRjrj }
$$$$
\left.+C i R i R i R j R j]+\left(1-d_{\mathrm{m}}{ }^{\prime}\right)\left[C i R i r i R^{\prime} j .+C i R i R i R^{\prime} j .\right]\right]
$$$$
+\left(1-d_{\mathrm{m}}{ }^{\prime}\right)\left[\text { CiR }^{\prime} \text { irirjirj }+ \text { CiR }^{\prime}\right. \text { iRirjrj }
$$$$
+\left(1-d_{\mathrm{m}}\right)\left[C_{i R^{\prime}} i r i R j r j+C^{\prime} R^{\prime} i r i R j R j+C^{\prime} R^{\prime} i R i R j r j\right.
$$$$
\left.+C i R^{\prime} i R i R j R j\right]+\left(1-d_{\mathrm{m}}{ }^{\prime}\right)\left[C^{\prime} i R^{\prime}{ }^{\prime} i R^{\prime} j\right. \text {. }
$$$$
\left.+C^{\prime} R^{\prime} i R i R^{\prime} j .\right] \text {; }
$$

with $(i, j)=(1,2)$ and $(2,1)$.

\section{Three-locus model for the control of sex}

Notations are the same as in the text and in Table 2. The deleterious effects of restorer alleles have the same values for $R 1$ and $R 2$.

The relative frequencies of genotypes in ovules at the next generation are:

for ovules C1r1r2m: [C1r1r1r2r2mm+ $\frac{1}{2}$. C1r1r1r2r2Mm]

$+\frac{1}{2}\left(1-d_{\mathrm{f}}\right)\left[C 1 r 1 r 1 R 2 r 2 m m+\frac{1}{2} . C 1 r 1 r 1 R 2 r 2 M m\right]$

$+\beta \cdot \frac{1}{2}\left(1-d_{f}\right)[C 1 R 1 r 1 r 2 r 2 m m$

$\left.+\frac{1}{2}\left(1-d_{\mathrm{f}}\right) C 1 R 1 r 1 R 2 r 2 \mathrm{~mm}\right]$ for ovules C1r1R2M: $\left(1-d_{\mathrm{f}}\right)\left[\frac{1}{4}\right.$. C1r1r1R2r2Mm

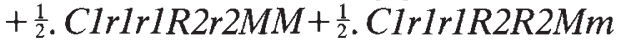

$+C 1 r 1 r 1 R 2 R 2 M M]$; etc.

Ovules $C 1 R 1 . M$ and $C 2 . R 2 M$ cannot exist because the individuals $C 1 R 1 \ldots M$. and $C 2 . . R 2 . M$. are male. Genotypes CiRiRi..MM do not exist either.

The relative frequencies of genotypes in pollen at the next generation are:

for pollen $r 1 r 2 m: \alpha \cdot \frac{1}{2}\left(1-d_{\mathrm{m}}\right)[$ CiRirirjimm

$+\frac{1}{2}\left(1-d_{\mathrm{m}}\right)$ CiRiriRjrjmm $]+\frac{1}{2}\left(1-d_{\mathrm{m}}\right)$

$\left[\right.$ CiRirirjigMm $+\frac{1}{2}\left(1-d_{\mathrm{m}}\right)$ CiRiriRjriMm],

with $(i, j)=(1,2)$ and $(2,1)$;

for pollen $R 1 r 2 M:\left(1-d_{\mathrm{m}}\right)\left[\frac{1}{4}\right.$. CIR1r1r2r $2 M m$

$\left.+\frac{1}{2} . C 1 R 1 r 1 r 2 r 2 M M+\frac{1}{2} . C 1 R 1 R 1 r 2 r 2 M m\right]$

$+\frac{1}{2}\left(1-d_{\mathrm{m}}\right)^{2}\left[\frac{1}{4} . C 1 R 1 r 1 R 2 r 2 M m+\frac{1}{2} . C 1 R 1 r 1 R 2 r 2 M M\right.$

$\left.+\frac{1}{2} . C 1 R 1 R 1 R 2 r 2 M m\right]+\frac{1}{2}\left(1-d_{\mathrm{m}}\right)^{2}{ }_{4}^{1} \cdot C 2 R 1 r 1 R 2 r 2 M m$

$+\frac{1}{2} . C 2 R 1 r 1 R 2 r 2 M M+\frac{1}{2} . C 2 R 1 R 1 R 2 r 2 M m$

$+C 2 R 1 R 1 R 2 r 2 M M]$; etc.

The frequencies of genotypes at the next generation are obtained as above.

total ovules $=$ Ciririrjrj.. $+\left(1-d_{\mathrm{f}}\right)$ CiririRj...

$+\beta\left(1-d_{\mathrm{f}}\right)$ CiRi. rjrjmm $+\beta\left(1-d_{\mathrm{f}}\right)^{2}$ CiRi.Rj. mm; with $(i, j)=(1,2)$ and $(2,1)$;

total pollen $=\alpha\left(1-d_{\mathrm{m}}\right)$ CiRi. rjirjm

$+\alpha\left(1-d_{\mathrm{m}}\right)^{2}$ CiRi.Rj. $m m+\left(1-d_{\mathrm{m}}\right)$ CiRi. rirjM.

$+\left(1-d_{\mathrm{m}}\right)^{2}$ CiRi.Rj.M.; with $(i, j)=(1,2)$ and $(2,1)$. 